\title{
"Para que les den libre paso en todas partes sin que los abran ni deten- gan": libros para las comunidades religiosas de la Nueva España
}

\author{
Idalia García ${ }^{1}$
}

Recibido: 3 de abril de 2017 / Aceptado: 13 de junio de 2017

Resumen. La adquisición de libros para las bibliotecas de comunidades religiosas en la Nueva España, sigue siendo un tema prácticamente desconocido. Toda la evidencia muestra que dichas comunidades siguieron los mismos procedimientos que se exigían a libreros y mercaderes de libros. Entre estos, la presentación de una memoria de libros y una revisión de los cajones, al principio y al final de la travesía. Tales testimonios evidencian la conformación de unas colecciones ricas y variadas, y de otras actividades relacionadas como la venta de libros, tanto de aquellos producidos bajo el patronazgo de órdenes religiosas como de libros duplicados en sus bibliotecas. En este texto pretendemos contribuir a nuestro conocimiento sobre la adquisición de libros en la América Española, través de algunos documentos conservados.

Palabras clave: comercio de libros; conventos; bibliotecas religiosas; bibliotecas conventuales; Nueva España.

\section{[en] "To give them free passage everywhere without opening or stopping":} Books for the Religious Communities of New Spain

\begin{abstract}
The acquisition of books for the libraries of religious communities in New Spain, remains a subject almost unknown. All evidence shows that such communities followed the same procedures required of booksellers and merchants. Among these, the presentation of one list of book and a review of the boxes, at the beginning and end of the journey. Such testimonies show us the formation of rich and varied bibliographic collections and other related activities like the sale of books, both those produced under the patronage of religious orders and duplicate books in their libraries. In this text we intend to contribute to our knowledge about the acquisition of books in the Spanish America, through some preserved documents.
\end{abstract}

Keywords: Book trade; Convents; Religious libraries; Convent libraries; New Spain.

Sumario. 1. La cultura del libro en la Nueva España. 2. El comercio libresco. 3. Los libros en las órdenes religiosas de la Nueva España. 4. Las adquisiciones librescas de los religiosos. 5. Una reflexión final: los libros necesarios.

Cómo citar: García, I. (2017) "Para que les den libre paso en todas partes sin que los abran ni detengan": libros para las comunidades religiosas de la Nueva España, en Cuadernos de Historia Moderna $42.1,151-173$.

\footnotetext{
Universidad Nacional Autónoma de México pulga@iibi.unam.mx
} 
Nueva España era un inmenso territorio del que era posible apropiarse mediante la acción de los frailes y las extensas redes introductorias del ideal religioso y civilizador creadas por ellos.

Guillermo Tovar de Teresa (2006)

\section{La cultura del libro en la Nueva España}

Lo que queda de las bibliotecas de la Nueva España son unos cuantos objetos bibliográficos dispersos en numerosas colecciones nacionales y extranjeras. Sin embargo, estos son testigos de la conformación de colecciones bibliográficas en todo el territorio novohispano. Bibliotecas grandes y pequeñas se fueron armando en los espacios privados, pero también entre las comunidades religiosas. Estas, las de regulares, existieron desde el siglo XVI y hasta el siglo XIX cuando las Leyes de Reforma cerraron todas las comunidades religiosas. Fue entonces cuando esas bibliotecas comenzaron a dispersarse por todo el mundo, pero también comenzó una destrucción que no finalizó formalmente sino hasta finales del siglo XX. En efecto, dichas colecciones no han sido estudiadas con profundidad pese a su riqueza bibliográfica. Esta carencia de información no permite comprender cómo se integraron y por qué fue tan triste su destino. Ciertamente, hasta fecha muy reciente, los libros que quedan en México de todas estas colecciones religiosas se han comenzado a catalogar. Un trabajo que ha demostrado que conservamos verdaderas rarezas bibliográficas y objetos únicos que han desaparecido en otros países.

Dichos libros son rastros que quedan del pasado de la cultura novohispana. Una historia que comenzó con los libros que trajeron desde sus primeros viajes conquistadores, colonizadores y evangelizadores en petacas y cajones. Una aventura que ha sido narrada y documentada por estudiosos como Irving A. Leonard ${ }^{2}$ y otros. Poco tiempo pasó para que esos polizones librescos o compañeros inseparables, comenzaran a constituir comunidades de lectores que llamaron poderosamente la atención de mercaderes y libreros europeos. Personajes que ya habían constituido verdaderas redes comerciales que cruzaban toda Europa desde que la prensa tipográfica había mostrado sus virtudes. Entre estas, fue siempre un mercado apetecible y rentable pero riesgoso. Razón por la cual esos mercaderes obtuvieron de la Corona Española la concesión de no pagar impuestos por su comercio desde 1480. Merced que también se mantuvo para el comercio interoceánico desde 1548, pero no estuvieron exentos del pago de la avería al cambiar de mulas a barcos como medio de transporte. La avería aseguraba las mercancías y al medio de transporte de cualquier trágica eventualidad que pudiera ahogar los sueños de un negocio interoceánico.

Gracias a estos aventureros y emprendedores se consolidó toda una cultura del libro en el territorio novohispano. Los libros llegaron a pueblos y ciudades desde Guatemala a las Filipinas pese a todos los impedimentos, humanos y naturales. Desde 1539, que se estableció el primer taller de imprenta en la capital virreinal, los libros comenzaron a producirse sin cesar hasta 1820, cuando aproximadamente se calcula que terminó la producción de las prensas tipográficas en el México virreinal. Ciertamente los establecimientos novohispanos nunca fueron tan competitivos como

LeOnARD, I. A.: Los libros del conquistador, México, FCE, 2006, p. 159. 
los grandes centros tipográficos de Europa. No obstante, fueron capaces de abastecer a un mercado local en prácticamente todas las áreas del conocimiento.

Esta capacidad se puede apreciar precisamente en el número de edictos inquisitoriales conservados, puesto que estos debían pegarse en las puertas de catedrales, iglesias y parroquias para asegurar su pleno conocimiento. Numerosos libros de los talleres novohispanos han desaparecido por lo que suponemos que las tiradas nunca fueron muy grandes y que estarían dedicadas a un mercado local. En efecto, tenemos poca información y escasas evidencias al respecto ${ }^{3}$. Pese a esto, existe una diferencia sustancial entre la documentación conservada sobre libros producidos en la Península Ibérica y aquellos del territorio novohispano. Es precisamente en esté último, que se registró una presencia constante de los impresos producidos en la Nueva España.

Por otro lado, algunos de estos talleres también se dedicaron al comercio de libros. Lo sabemos porque las autoridades inquisitoriales pidieron la entrega de una memoria de los libros en venta a libreros y mercaderes de libros. Instrucción que se estableció desde la publicación del índice de libros prohibidos de 1612. Esta relación debía ser alfabética y comenzar por los nombres de los autores. Afortunadamente conservamos un número importante de estas relaciones en el Archivo General de la Nación de México (AGN). En algunos casos se conservan varias memorias elaboradas por un sólo negocio, entre las que se encuentran las de Paula de Benavides, viuda de Bernardo de Calderón, y otras de los libreros Francisco Rodríguez Lupercio y Agustín de Santiesteban. No olvidemos que los Calderón fueron la dinastía de impresores más longeva de la Nueva España ${ }^{4}$, mientras que Lupercio y su colega aparentemente tenían uno de los modestos talleres de imprenta del siglo XVII ${ }^{5}$. Sin embargo no podemos sostener esta última afirmación, pues ambos personajes no han sido estudiados.

También se conservan algunas memorias de aquellas personas dedicadas exclusivamente a la venta de libros, como Simón del Toro de la familia sevillana de Antonio del Toro ${ }^{6}$, de imprentas famosas como la Biblioteca Mexicana, o de algunos mercaderes menos conocidos como Alonso de Pereira o Pedro de la Calle ${ }^{7}$. Lo anterior significa que las reglas se aplicaron para todos los que de alguna manera comerciaban con el libro. Tristemente, una parte de esos testimonios de libreros y lectores siguen sin análisis. Es decir, no se han transcrito, tampoco se han identificado las ediciones registradas y mucho menos se ha intentado explicar o darle sentido con una perspectiva cultural. Desde luego, estas evidencias contienen datos más que interesantes sobre la producción y circulación de libros en el México colonial.

Este mercado interoceánico ofertó libros en el territorio novohispano que alimentaron las bibliotecas privadas e institucionales en este espacio geográfico. No tenemos certeza de cuántas bibliotecas existieron, básicamente porque no ha sido un tema de interés para la investigación histórica, por lo que ni siquiera sabemos cuáles son las fuentes conservadas. Sin embargo, las evidencias hasta ahora estudiadas

GARCíA, I.: “Atrás de la escena tipográfica: los impresores en la Nueva España”, Investigaciones Bibliotecológicas, 29-66 (2015), p. 119.

4 Ward, K.: Where They Coin Money and Print Books: The Calderón Family Printing Dynasty, 1631-1732, Tesis doctoral. University of Texas, 2013, http://repositories.lib.utexas.edu/handle/2152/26062 [Fecha de consulta: 7 Abril de 2015]

5 Medina, J. T.: La imprenta en México, 1539-1821, México, UNAM, 1989, t. 1, p. CXXXVI. Edición facsimilar.

6 Rueda Ramírez, P.: "El librero sevillano Antonio de Toro en el negocio del libro con América durante el siglo XVII", en Gutiérrez Lorenzo, M. P. (coord.): Impresos y libros en la historia económica de México (siglos XVI$X I X)$, Guadalajara, Jalisco, Universidad de Guadalajara, 2007, pp. 41-75.

Zahar Vergara, J.: Historia de las librerías de la ciudad de México. México, UNAM, 2006, pp. 8-22. 
muestran que fueron colecciones con distintos materiales y, por supuesto, que en sus contenidos puede apreciarse prácticamente todas las disciplinas del conocimiento de su época. Indudablemente que algunas bibliotecas privadas fueron trasladadas desde la península. Así fue en 1695, cuando el licenciado don Baltasar de Tovar, trasladó su colección al ser nombrado Fiscal de lo Civil en la Real Audiencia de México ${ }^{8}$. Es muy posible que esta biblioteca haya crecido con los años de trabajo en América, pues el fiscal Tovar llegó a ser responsable del Juzgado de Bienes de Difuntos en la Nueva España. Lamentablemente de esta colección no hemos encontrado mayor información como para determinar los aumentos o disminuciones de libros.

De otras colecciones tenemos diferentes noticias, como las relacionadas con la adquisición de libros en Europa. Así, el 10 de enero de 1688 Joseph de Villalta, informó que le habían llegado a la aduana novohispana dos libros nuevos: "Uno de la Vida del Venerable padre frai Sebastian de Aparicio. Y otro de la Vida del venerable padre frai Bernardino de Corvera [ ] y en los mismos cuatro cajones vienen unos libros de las obras de la Venerable Madre María de la Antigua". Dichas noticias sólo indican que hay lectores adquiriendo libros recientes para sus bibliotecas. Las ediciones sevillanas de los venerables aquí citadas, fueron impresas el año anterior mientras que la última es probable que se trate de la edición de 1678. Las obras europeas alimentaron colecciones de las que a veces no tenemos más noticias. En este sentido existe un solo caso que podemos documentar: la biblioteca del médico José Peredo, de quién se conserva un documento relativo al traslado de sus libros desde Oaxaca que no está fechado ${ }^{10}$, y la memoria de sus libros que se elaboró a su muerte en $1782^{11}$.

El trabajo de archivo muestra que la mayor información sobre estas colecciones, procede de los trámites inquisitoriales que se hacían a la muerte de un lector. No se trata de inventarios post mortem, documentos que han sido utilizados desde hace años en diversas latitudes para estudiar las bibliotecas antiguas como muestran trabajos de Trevor J. Dadson, Fernando Bouza o José Luis Barrio Moya. En la documentación novohispana encontramos otro testimonio, escasamente mencionado ${ }^{12}$, aunque se trate también de un proceso necesario para la sucesión patrimonial. Nos referimos al trámite inquisitorial que fue necesario sí un heredero o albacea pretendía vender los libros de una persona.

Estas memorias de libros no tienen el mismo carácter jurídico que un inventario y esa es su principal diferencia. No obstante a esto, fue un trámite que formó parte de los mecanismos de control que la Inquisición estableció no sólo en la península sino también en los territorios americanos. Al parecer esta normativa, tuvo una aplicación o interpretación diferente en España, pues sólo sí un librero encontraba libros prohibidos al tasar una colección privada estaba obligado a entregarlos a la Inquisición ${ }^{13}$.

\footnotetext{
Memoria de los libros que en tres cajones lleva a la Nueva España el Licenciado Don Baltasar de Tovar Fiscal de lo Civil de la Real Audiencia de México (1695), Archivo General de la Nación (en adelante AGN), Indiferente virreinal, caja 0791, exp. 013, fols. 16r-18r. Expediente digitalizado.

$9 \quad$ Solicitud de Joseph Villalta ante el Tribunal del Santo Oficio (1688), AGN, Indiferente virreinal, caja 4849, exp 5, fol. 9r.

10 José Peredo profesor de Medicina en Oaxaca remite dos cajones de libros de su uso y solicita le sean entregados, AGN, Inquisición 1159, exp. 4, fols. 78r, 81r-84v.

11 Memoria de libros del difunto José Peredo (1782), AGN, Inquisición 1268, exp. 3, fols. 153r, 154r-161v.

12 Peña DíAz, M.: Escribir y prohibir: inquisición y censura en los Siglos de Oro, Madrid, Cátedra, 2015, p. 42 y 239.

13 Pardo, T.: Ciencia y censura: la Inquisición Española y los libros cientificos en los siglos XVI y XVII, Madrid, CSIC, 1991, p. 36.
} 
El incumplimiento de esta instrucción, implicó cuando menos "la excomunión y el abono de cincuenta ducados para el Santo Oficio" ${ }^{14}$. No tenemos noticia de que se hayan elaborado o conservado documentos relativos a este proceso español, cuando menos todavía no se han estudiado. Recordemos que el Tribunal del Santo Oficio podía actuar solamente frente a libros, impresos o manuscritos, que estuvieran en circulación. También es importante apuntar que para la inquisición española existieron dos tipos de libros bajo persecución: los prohibidos y los expurgados. Estos dos aspectos son importantes para comprender la censura de libros en la Nueva España. De esta manera en 1632, se introdujo por primera vez la atención a las "librerías antiguas" en la edición del Index promovido por el Inquisidor General Antonio Zapata ${ }^{15}$.

En ese momento se creyó conveniente apuntar el peligro que representaban los libros cuando pasaban de mano en mano sin la revisión del Santo Oficio. Esto fue porque la posibilidad de que algunos lectores tuviesen licencias para leer libros prohibidos, y eso significaba que cierta lectura peligrosa podría deambular libremente con su venta sin control. Gracias a esta preocupación se conservan numerosas memorias como evidencia de ricas colecciones en el entorno particular novohispano. Un buen ejemplo de lo anterior, es la memoria que presentó el librero José Cueto de la biblioteca del abogado Luis de Mendoza en $1777^{16}$. Una colección con casi dos mil títulos registrados. Un documento en el que debe destacarse que el librero anotó puntualmente autores, títulos, ciudades de impresión y años.

Los documentos que presentan de esta manera la información, no son tan frecuentes en las memorias elaboradas entre el siglo XVI ${ }^{17}$ y el XVIII. Sin embargo hemos podido confirmar que fueron los inquisidores, quienes gradualmente solicitaron mayor información en estas memorias desde 1612. Para septiembre de 1770, reiteraban que debía entregarse "lista circunstanciada de los libros que tengan, por orden alfabetico, con expresion del nombre de los Authores, tiempo y lugar de las impresiones"18. Dicha instrucción siempre estuvo dedicada a quienes introducían libros en los territorios o quienes tenían librería.

Sin embargo, los documentos conservados informan que existió un número importante de casos, de libreros y de lectores, que informaron de las ediciones que tenían en ese momento con el detalle solicitado. También es cierto que no hemos encontrado ninguna noticia o normativa inquisitorial que castigue o sancione, que las memorias de libros no tuvieran los lugares de impresión o los años. Por tanto, esos datos dependerían de quién elaboraba esa relación ya fuese religioso, tasador, librero, mercader, calificador, inquisidor o un simple lector. Desconocemos la razón por la cual algunas personas aportaban todos los datos que requería la Inquisición y otras no, cuestión que por ahora seguirá siendo un misterio.

14 Rodríguez Besné, J.: El Consejo de la Suprema Inquisición: perfil jurídico de una institución, Madrid, Editorial Complutense, 2000, p. 232.

15 Zapata, A. (ed.): Novus index librorum prohibitorum et expurgatorum... Hispali: ex typographaeo Francisci de Lyra, 1632. Ejemplar de la Universidad Complutense (BH DER 6892), disponible en Google Books. fol. 10v.

16 Libros del licenciado don Luis de Mendoza, Abogado que fue de la Real Audiencia de esta Corte (1777), AGN, Inquisición 1183, exp. 13, fols. 366r-400v.

17 Pedraza Gracia, M.: "Lector, lecturas, bibliotecas...: el inventario como fuente para su investigación histórica", Anales de documentación: Revista de biblioteconomía y documentación, 2 (1999), p. 146, http://revistas.um.es/ analesdoc/article/view/2611 [Consulta: 14 de Mayo de 2016].

18 Formulario de edictos en los que se dice que el Tribunal del Santo Oficio debe evitar que se introduzca el pestífero daño de herejía y libertinaje a través de falsos dogmas en libros que se presentan con nombres disfrazados, así que deben evitar los libros con nombres prohibidos (1770), AGN, Indiferente virreinal, caja 301, exp. 2, fol. 149v. 
Por otro lado, las bibliotecas institucionales representan un universo fascinante desde muchos aspectos. En primer lugar, porque reflejan una vida cultural muy activa en las órdenes religiosas, de la que tenemos noticia gracias a algunos inventarios conservados en bibliotecas y archivos. Así, sabemos que existieron bibliotecas religiosas en prácticamente todo el territorio novohispano, y no sólo en las grandes fundaciones de franciscanos, dominicos, jesuitas, carmelitas o mercedarios, entre otros. En el mundo secular, también hubo colecciones en catedrales y seminarios, por citar sólo otros espacios. Como hemos dicho, quedan muchos libros de estas colecciones en nuestras bibliotecas, públicas y privadas. Dichos objetos poseen evidencias históricas que permiten relacionarlos con una o varias de estas colecciones. La suma de ambos testimonios, bibliográficos y documentales, testimonia un rico legado bibliográfico conformado durante casi trescientos años.

Las colecciones de los regulares, también son el resultado de complejas redes de comunicación que los religiosos establecieron entre todas sus fundaciones. Esos caminos hacían posible abastecer necesidades de las comunidades como alimentos, ropa, obras artísticas y también libros mediante "unas rutas alternativas al mercado oficial" ${ }^{19}$. En efecto, Rueda ${ }^{20}$ ya había mostrado la participación de los religiosos en la Carrera de Indias, especialmente procuradores, quienes fueron responsables de la salida de varios cajones de libros desde Sevilla.

Lo anteriormente expuesto muestra que no sólo los jesuitas tenían organizadas redes de intercambio, capaces de satisfacer todas las necesidades de sus casas en cualquier territorio. Mediante estas, llegaron cajones de libros destinados no sólo a las bibliotecas institucionales sino también a las colecciones privadas que existían en las diversas fundaciones religiosas de toda la América Española. Un traslado que ha quedado bien documentado, como para poder precisar algunas de sus características $\mathrm{y}$, especialmente, identificar las obras que interesaban a los regulares de la Nueva España.

\section{El comercio libresco}

La complejidad del comercio entre América y Europa, así como los intereses económicos que estaban en juego, justificaron la fundación de la Casa de la Contratación en 1503. Dicha entidad estaba destinada a fiscalizar y regular tanto ese comercio como el tránsito de los pasajeros de Indias. Los libros tenían además sobre sí la sospecha que podían transmitir la herejía y las ideas erróneas. De ahí que, desde 1506, Fernando el Católico prohibiera la exportación de obras profanas ${ }^{21}$, más adelante se prohibirían las obras de caballerías y finalmente también las obras en romance e historias vanas. La intención de estas medidas fue que los naturales de las tierras americanas no pusieran en duda las Sagradas Escrituras, que estaban impresas igual que aquellos libros. Pese a todas estas medidas los libros siguieron circulando entre

19 Alcalá Donegani, L. E.: "De compras por Europa: Procuradores jesuitas y cultura material en Nueva España”, Goya. Revista de Arte, 318 (2007), p. 142.

20 Rueda Ramírez, P.: "Libros a la mar: El libro en las redes comerciales de la Carrera de Indias", en CASTILlO Gómez, A. (ed.): Libro y lectura en la Península Ibérica y América, [Valladolid], Junta de Castilla y León, Consejería de Cultura y Turismo, 2003, p. 203.

21 Rueda Ramírez, P.: Negocio e Intercambio cultural: el comercio de libros con América en la Carrera de Indias, siglo XVII, Sevilla, Diputación. Universidad, 2005, p. 34. 
ambos continentes. Al final, se trataba de una mercancía y de intereses económicos que no estaban al servicio ni de Dios ni de la Corona, sino de familias que sustentaban su alimento en el comercio de los libros. Dicha constante demandaba que las autoridades civiles, reiteraran una y otra vez las prohibiciones, pero también que implementaran nuevas normas.

Desde 1503, los mercaderes estaban obligados a registrar sus mercancías antes de embarcar. Ese registro fue la justificación legal de toda transacción comercial interoceánica y, respondía a una normativa específica que debía cumplir toda persona interesada en enviar mercancías a los territorios de la América española. Para ello el interesado debía tramitar dos licencias. Una correspondiente a los trámites aduanales (la hoja de registro) y otra que le permitía embarcar los objetos (la memoria de las $\operatorname{cosas})^{22}$. Esta última requería un registro de la mercancía, del cargador y del puerto de destino. Como se ha dicho, los libros fueron una mercancía exenta del pago del almojarifazgo pero no de la avería ${ }^{23}$.

En principio, los registros eran generales y sólo referían al nombre del mercader y el número de cajones que transportaba. La preocupación por los efectos sociales que causaban los libros, propició que poco a poco esos registros se pidieran cada vez más detallados. Igualmente en 1550 se ordenó que los cajones de libros que se enviaban a América se abrieran y revisaran en relación con el registro entregado ${ }^{24}$. Esta fue una condición comercial que bien supo aprovechar el Tribunal del Santo Oficio, pues desde 1547 adquiriría nuevas potestades respecto al control de los libros. Así, con la publicación del Î́ndice de libros prohibidos en 1559, adquirió autoridad plena para revisar esa misma lista de libros que hemos mencionado. La memoria que especificaba qué libros y cuántos iban en cada cajón.

El proceso de revisión inquisitorial iniciaba justo cuando se terminaba el trámite de los libros exclusivamente como mercancías. Después de los pagos y registros establecidos, el mercader o responsable de estos debía ir con los inquisidores, en Sevilla o Cádiz, donde presentaba la lista de los títulos que contenía cada cajón. Ahí, un calificador revisaba ese registro, buscando libros prohibidos para autorizar su transporte. Con la autorización el cargador volvía a la aduana para que se pusiera a los cajones el sello del Santo Oficio. Así se establecía que no se habían encontrado libros perniciosos y entonces los cajones se embarcaban al Nuevo Mundo ${ }^{25}$. Aparentemente en este proceso, descrito en múltiples ocasiones, no se revisaban los libros que había dentro de los cajones sino exclusivamente la relación de los mismos.

Por su parte, cuando los libros llegaban al puerto de destino también debían obtener autorización de salida, ya que el sello inquisitorial no debía haberse roto. Es justo cuando encontramos noticias de que efectivamente los libros eran revisados además de su relación ${ }^{26}$. Igualmente había un proceso de control inquisitorial, sí los libros

\footnotetext{
Ibidem, p. 43.

23 González Sánchez, C. A.: Los mundos del libro: medios de difusión de la cultura occidental en las Indias de los siglos XVI y XVII, Sevilla, Universidad, Diputación, 1999, pp. 51-52.

24 Veitia Linage, J.: Norte de la contratacion de las Indias occidentales, Con privilegio en Sevilla, Por Juan Francisco de Bas, 1672, pp. 193-195. Ejemplar de Austrian National Library, http://data.onb.ac.at/rec/ AC10396466, disponible en Google Books.

25 Maillard Álvarez, N.: "Estrategias de los profesionales del libro sevillanos ante el Santo Oficio: entre la evasión y la colaboración", en RuEDA, P. (dir.), El libro en circulación en el libro moderno en España y Latinoamérica, Madrid, Calambur, 2012, pp. 36-37.

26 El Santo Oficio envía a el Maestro Jacinto de Guevara, unos cajones para que de su parecer (1665), AGN, Inquisición 513, exp. 30, fol. 2r.
} 
se enviaban a otra parte del territorio. Entonces debía nuevamente entregarse el registro, indicando de quién eran los libros, cuál era la marca (no la del Santo Oficio) que distinguía a los cajones y quién los transportaba ${ }^{27}$. Nuevamente los inquisidores revisaban tanto la lista como los cajones.

Condición que no todos cumplían, lo que obligaba a los inquisidores a ratificar la instrucción cada vez que había denuncias al respecto. En doce de octubre de 1660, se publicó un edicto porque el licenciado Juan Ortega Montañés se había presentado ante la Inquisición novohispana:

[ ] diziendo tener cierta ciencia, y noticias individuales, que en la Flota, que estaba en San Juan de Ulua Puerto de la Nueva Veracruz, avia venido grandissimo numero de caxones de libros, sin que sus dueños trajessen las licencias que debian, y si traian algunas eran diminutas, y otras sin la forma devida, y que no avian exhibido inventario alguno al Comisario de este Santo Officio de la dicha Ciudad ${ }^{28}$.

De cualquier manera sólo se podía comerciar con libros autorizados, mediante estos registros y peticiones que afortunadamente conservamos. Son testimonios que aportan numerosos datos no sólo sobre los libros que circularon en ese periodo, sino también de las personas involucradas en esas redes comerciales, así como qué tipo de obras se comerciaban. Algunas evidencias pueden parecer curiosas, como la que envío en 1612 Juan Bautista Rendón:

Joan baptista rendon Vezino desta ciudad digo que yo traigo En esta presente flota dos caxones de libros numero Vno Y dos marcados con la marca de fuera que Son los conthenidos En La memoria que Presento Sin acordarme de las Ympresiones ni años Los quales Pase con licencia del santo officio de sevilla abiendo seVisitado Por mandado del en la dicha çiudad la qual dicha licencia esta firmada delos señores Ynquisidores del y hasta a ora no an benido de la Veracruz ni se quien los traiga que las deje encomendadas a Alonso de Labasa scrivano de la nao nuestra señoria de la concepcion de la flota deste presente año deseisçientos y Doze general Juan guttierres de Garibay Los quales luego que lleguen dare noticia aVuestra Señoria Sin que se abran Para que SeVean Por quien Vuestra Señoria mandare a quien Suplico Se Sirva de admitir esta mi manifestaçion Y ordenar que adonde Los an de llevar para que Se bean. Joan baptista Rendon ${ }^{29}$.

Lamentablemente en este caso la memoria citada se ha extraviado y no es el único ejemplo que podríamos citar. Muchas memorias de libros se han perdido o mezclado con otros expedientes del AGN. Es difícil explicar esos extravíos, sí fueron resultado de trámites de la época o la consecuencia de movimientos y procesos de organización contemporáneos. Afortunadamente todavía podemos acceder a trámites que sí la poseen y con ello, entender muchos detalles de este comercio, pues a partir de

$27 \quad$ Factura de dos cajones de libros que con la marca y números del margen de orden del señor doctor don Luis Beltrán, remito a la ciudad de México con el arriero don Juan Fernández de Peredo (Sin fecha), AGN, Indiferente virreinal, caja 5599, exp. 123, fol. 1r. Documento digitalizado.

28 Edicto que exhorta a todos los vecinos y moradores que habitan el distrito y declaren si han traído libros para sí, para estas personas o para vender, así como donde paran o han parado, so pena de excomunión mayor (1660)". AGN, Indiferente virreinal, caja 286, exp. 5, fol. 38r. Documento digitalizado.

29 Listas de libros presentados al Santo Oficio de la Inquisición, en cumplimiento del Edicto de 20 de Octubre de 1612. México, AGN, Indiferente virreinal, caja 4217, exp. 42, fol. 5r. Expediente digitalizado. 
1583 se comienza a cumplir de forma más regular las instrucciones. Justo "a partir de la aparición del prohibitorio y expurgatorio de Quiroga (1583 y 1584)"30.

El mismo proceso fue obligatorio para cualquiera que comerciara libros, ya fuese un cajón de libros diferentes o una parte completa de cierta edición. Esto hizo en 1699, Joseph de Olayzola y vecino de Sevilla, quien informaba a los inquisidores su deseo de trasladar a la Nueva España un cajón de libros en los que iban

[ ] sesenta tomos del Artifice Perfecto, vida del Hermano Francisco Díaz del Rivero. Y otros doce tomos de la vida de San Estanislao y quatro tomos de la vida del Cardenal Espinola impresos en esta ciudad y Autor de todos el padre Gabriel de Aranda de la Compañia de Jesus ${ }^{31}$.

Es evidente que estos tomos estaban dedicados a alimentar librerías novohispanas, las cuales eran tan diversas que iban desde un simple cajón hasta un establecimiento con miles de libros puestos a la venta. El comercio de libros no fue tan despreciable como podía suponerse, aunque todavía falta mucho por saber. De lo único que tenemos certeza es que se realizó en prácticamente todas las ciudades y pueblos de la Nueva España. Los libros llegaron a sus lectores en las recuas de los arrieros, como notifican varios testimonios.

Últimamente se han identificado numerosos personajes dedicados a la venta de libros en este virreinato, activos desde finales del siglo XVI y hasta principios del siglo XIX. Recientemente tuvimos noticia del mercader Felipe Pérez del Campo que, a diferencia de otros, distribuía su mercancía prácticamente de casa en casa ${ }^{32}$. Lamentablemente son muy pocos los libreros que han motivado algún interés de estudio específico. Además del citado encontramos trabajos dedicados a las librerías de Agustín Dhervé33, Luis Mariano de Ibarra ${ }^{34}$, Cristóbal de Zúñiga y Ontiveros ${ }^{35}$, Paula de Benavides ${ }^{36}$ y Bartolomé de Mata $^{37}$. Estos dos últimos trabajaron durante el siglo XVII, y se suman a otros trabajos que de manera general, habían delineado ciertas características de este tipo de comercio $^{38}$.

30 GonzÁlez SÁnchez, op. cit. (nota 23), p. 54.

31 Varias solicitudes de licencias al Santo Oficio (1665-1699), AGN, Indiferente virreinal, caja 791, exp. 13, fol. 23r. Expediente digitalizado.

32 García, I. y Montiel Ontiveros, A. C.: "Una vida entre cajones de libros: Felipe Pérez del Campo en la Nueva España”, Estudios de Historia Novohispana, 43 (2010), pp. 51-107, www.historicas.unam.mx/publicaciones/ revistas/novohispana/pdf/novo43/523.pdf [Consulta: 23 de Noviembre de 2016]

33 Megged, A.: "Revalorando las Luces en el mundo hispano: la primera y única librería de Agustín Dhervé a mediados del siglo XVIII en la ciudad de México", Bulletin Hispanique 101-1 (1999), pp. 147-173, www. persee.fr/doc/hispa_0007-4640_1999_num_101_1_4998 [Consulta: 4 de octubre de 2016]

34 Moreno Gamboa, O.: Historia de una librería novohispana del siglo XVIII, Tesis de Maestría en Historia, UNAM, Facultad de Filosofía y Letras, 2006.

35 SuÁrez Rivera, M.: En el arco frontero al palacio: análisis del inventario de la Librería de Cristóbal de Zúniga y Ontiveros, 1758, Tesis de Maestría en Historia, UNAM, Facultad de Filosofía y Letras, 2009.

36 Santana Vela, J.: Un escaparate de la cultura letrada en la Ciudad de México: la Librería de Paula Benavides al mediar el Siglo XVII, Tesis de Maestría en Historia, UNAM, Facultad de Filosofía y Letras, 2013.

37 García, I.: "El trasiego de los libros en la Nueva España: Bartolomé de Mata y el comercio de libros entre el siglo XVI y el XVII“, en Congreso Internacional Gutierre González y el Renacimiento. Entre Roma y la Monarquía Hispánica, Jaén (España), Universidad de Jaén, Instituto de Estudios Giennenses y Fundación Santa Capilla de San Andrés. 2015. Inédito.

38 Rivas Mata, E.: "Impresores y mercaderes de libros en la ciudad de México, siglo XVII", en CASTAÑEDA, C. (coord.), Del autor al lector: historia del libro en México, México, CIESAS, CONACYT, Porrúa, 2002, 71-102. En la misma edición GonzÁlez GonzÁlez, E. y Víctor Gutiérrez RodríGuez, V.: "Libros en venta en el México de Sor Juana y de Sigüenza, 1655-1660”, pp. 103-132. 


\section{Los libros en las órdenes religiosas de la Nueva España}

Es todavía una tarea pendiente elaborar una lista completa de todas las colecciones bibliográficas que existieron en las casas, colegios, conventos, seminarios, eremitas, congregaciones o noviciados, conformadas por todas las órdenes religiosas en la Nueva España desde el siglo XVI. Relación que podemos compilar, juntando la evidencia de testimonios de procedencia, las noticias del expurgo realizado a estas bibliotecas en $1716^{39}$, la relación elaborada con base en la información extraída del Auto inquisitorial de $1802^{40}$, y los inventarios que se conservan y documentan el contenido de estas colecciones. La única relación que se ha hecho de algunos de estos documentos, elaborados entre el siglo XVII y principios del XIX, fue la que publicó Osorio hace más de veinte años ${ }^{41}$.

Ciertamente esta se ha quedado incompleta, pues las investigaciones recientes en archivos y los procesos de catalogación de colecciones de manuscritos, como la que existe en la Biblioteca Nacional de México, han aumentado gradualmente la lista. Sin duda, conservamos muchos más inventarios de la orden franciscana que de cualquiera otra comunidad ${ }^{42}$. Rafael Pérez, quien ha estudiado bibliotecas de conventos franciscanos en la Provincia de los Ángeles de España, apunta que algunos de los inventarios son resultado del capítulo de la Orden realizado en Toledo en $1646^{43}$. Por lo que parece de este lado del océano, los inventarios franciscanos fueron producidos por visitas eclesiásticas a las provincias novohispanas y están fechados entre 1629 y 1760 .

Una parte importante de los testimonios que informan sobre las bibliotecas de conventos y otras casas en la Nueva España responden a estas visitas que cada orden hacía para verificar el funcionamiento de sus fundaciones antes de la realización de un capítulo. Por tanto son documentos que relacionan todas las posesiones y gastos que se habían hecho en cada casa religiosa, incluyendo las bibliotecas. Otros responde a obligaciones establecidas en sus propias normativas. Las ordenes mendicantes en la Nueva España fundaron varias provincias religiosas en el territorio novohispano, destacándose por número las de los Franciscanos que fundaron las correspondientes al Santo Evangelio de México, San Pedro y San Pablo de Michoacán, del Santísimo Nombre de Jesús (para Guatemala, Honduras y Nicaragua), San José de Yucatán, San Francisco de Zacatecas y de Santiago de Jalisco. Por su parte los Dominicos, fundaron las provincias de Santiago de México, San Vicente de Chiapas y de Guatemala y San Hipólito de Oaxaca. Los Agustinos fundaron la Provincia del Santo Nombre de Jesús de México y San Nicolás de Tolentino de Michoacán. Los

39 Inquisición de México. Año de 1716. Quaderno de las calificaciones que remitieron los Provinciales de las Religiones de este Reyno de la Nueva España, y de las Yslas Philipinas, de haberse expurgado segun el Nuevo Expurgatorio el año de 1707, los libros de las Librerias de los Conventos de cada Provincia, y de los Religiosos particulares de ellos, AGN, Inquisición 763, exp. 2, fol. 131r.-313r.

40 Moreno Gamboa, O. y Reyes Ruiz O.: Comercio y circulación de libros en Nueva España: dos autos de la Inquisición de México (1757-1802), México, Benemérita Universidad Autónoma de Puebla, Ediciones Educación y Cultura, 2016.

41 Osorio Romero, I.: Historia de las bibliotecas novohispanas, México, SEP, Dirección General de Bibliotecas, 1986, pp. 264-274.

42 Morales, F.: "Cómo se formaron las bibliotecas franciscanas. Una mirada a través de la Biblioteca Franciscana de Cholula", Fundación Canaria Orotava de Historia de la Ciencia, p. 5, http://fundacionorotava.org/media/ uploads/files/163/01_Francisco_Morales.pdf [Consulta: 30 de mayo 2017]

43 García Pérez, R.: "La biblioteca del Convento de San Antonio de Padua: Libros de Autor Franciscano (1646)", Hispania Sacra, 57 (2005), 746. 
Mercenarios fundaron la Provincia de la Visitación y los Carmelitas la de San Alberto de Indias. Los jesuitas, también tenían estructuradas dos provincias: la Meridional y la de Sinaloa.

Esos inventarios junto con los libros conservados, constituyen testigos excepcionales, en tanto que son los últimos supervivientes que quedan de esas bibliotecas. Se trata de elementos que testimonian la existencia de colecciones bibliográficas complejas, grandes y pequeñas. Tales testimonios históricos también muestran la riqueza de estas bibliotecas, que deja atrás la idea de que fueron exclusivamente colecciones pobres, devotas y sin novedades.

Por el contrario, tan sólo "los conventos albergaban las más nutridas bibliotecas de las colonias, enormes y actualizadas colecciones donde era posible acceder a los más variados ramos de la cultura universal y seguir de cerca el movimiento intelectual europeo" ${ }^{\prime 4}$. Bibliotecas para comunidades, pero también donde existieron colecciones privadas que conformaban los propios religiosos. Estas últimas no eran contrarias a ninguna normativa, pues tenemos noticias de los libros en el entorno privado de la casa religiosa por su mención en algunas de las reglas y estatutos de las ordenes, en donde se puede leer que:

Aunque es licito a los religiosos tener el uso de los libros necessarios para su ministerio con licencia de su superior, mas no es cosa licita tener los Religiosos mas libros de los que son necessarios. Por tanto se ordena, que ninguna Religiosos pueda tener mas libros de los que según el juyzio del ministro provincial, conforme a la calidad de las personas fueren concedidos, $\mathrm{y}$ determinados ${ }^{45}$.

Esta práctica está presente en algunas anotaciones de propiedad conventual y de naturaleza privada que encontramos en los libros. Podemos citar al fraile que escribió en su libro: "Del uso de Fr. Manuel del Rosario de San Gerónimo. Costole su limosna. Fr. Thomas de Santa Maria"46. Dichas anotaciones resultan más interesantes en los espacios femeninos, pues son prácticamente la única evidencia física que se conserva de las bibliotecas de los conventos de monjas ${ }^{47}$. Contrario a lo que sabemos en los espacios masculinos, prácticamente no han quedado o localizado memorias de libros de las bibliotecas de monjas, y sólo hemos identificado dos marcas de fuego: las que corresponden a los conventos de Santa Clara de México y de Santa Catalina de Siena y Señora Santa Ana de Puebla.

44 Hampe Martínez, T.: "El eco de los ingenios: literatura española del siglo de Oro en las bibliotecas y librerías del Perú Colonial”, Foro Hispánico. Revista Hispánica de los Países Bajos, 4, 1992, p. 82.

45 Estatutos Generales de Barcelona para la familia cismontana de la Regular obseruancia de... San Francisco, vltimamente reconocidos y con mejor metodo dispuestos en la Congregacion general celebrada en... Segouia el año... de 1621... En Madrid: en la Imprenta Real, 1622, p. 23. Ejemplar de la UCM BH DER 6358, disponible en Google Books.

46 Anotación manuscrita en la portada del libro de CALATAYUd, P.: Doctrinas practicas que suele explicar en sus missiones... Dispuestas para desenredar, y dirigir las conciencias, para alivio de los curas, y rectores de almas en dar pasto espiritual a sus ovejas, para mayor expedicion de los confessores, y dilatacion de animo en oir confessiones, y para mayor facilidad, y menos trabajo de los missioneros, y predicadores evangelicos en predicar, segun Dios, y en instruir, y doctrinar practica, y oportunamente a los pueblos... En Valladolid: en la imprenta de la Congregación de la Buena Muerte, 1753. T. 1, Ejemplar de la Biblioteca Eusebio Francisco Kino (BEFK) 00444.

47 García, I.: "Soy del uso de la Hermana Mariana: testimonios bibliográficos de los conventos femeninos novohispanos", en Segundo Congreso Internacional. Los conventos de Monjas, arquitectura y vida cotidiana del Virreinato a la Post Modernidad, México, INAH, Coordinación Nacional de Monumentos Históricos, 2017 [En prensa]. 
Estas marcas, junto con las anotaciones manuscritas y los ex libris, también son testimonios de la existencia de las bibliotecas conventuales. Las primeras son evidencias excepcionales por el tipo de marcaje empleado en los libros, una técnica usada para el marcaje del ganado y aunque nos horrorice, también para los humanos. Estas marcas fueron ampliamente utilizadas en las bibliotecas de las comunidades religiosas novohispanas hasta el siglo XIX, aunque también conocemos algunas marcas empleadas en colecciones privadas. Las marcas de fuego que se relacionan con establecimientos de las ordenes religiosas son muy variadas, y se han separado básicamente en dos grupos: epigráficas y figurativas. Lo interesante es que existan marcas para cada fundación y no para cada orden. Es así que existen varias identificadas por cada casa religiosa. Actualmente no tenemos certeza si las marcas fueron empleadas sólo para ostentar la propiedad de los libros, o también pudieron usarse para indicar ciertos controles de lectura como la apropiada para Novicios. Sin embargo, las marcas resultan testimonios útiles para reconstruir las bibliotecas antiguas de las ordenes religiosas. Por su parte, sólo tenemos un ex libris de biblioteca conventual identificado. Es el que corresponde al Convento Grande de San Francisco de México. Hay otro que fue de la Biblioteca Turriana, una colección particular donada a la Catedral para uso público. Por otro lado, conservamos más anotaciones manuscritas de propiedad que certifican la posesión de un libro por una comunidad específica. Por ejemplo la nota que suponemos puso un bibliotecario: "Pertenece este Libro al Convento de el Carmen de Atrisco"48.

Existen otras tipologías documentales que aportan más noticia sobre estas bibliotecas. Entre estas se encuentran los inventarios realizados con la expulsión de la Compañía de Jesús, a partir de 1767. Estos suelen ser los más completos en información, justo porque así se pidió que se hicieran en las instrucciones de la Corona ${ }^{49}$. Los responsables de inventariar la biblioteca del Colegio de San Luis Potosí, cumplieron sobradamente con su tarea pues registraron incluso los libros que los jesuitas habían adquirido desde 1624. El detalle es excepcional en estos documentos:

17 Turriani (Reverendo Padre Maestro Francisco de la Compañia). Adbersus Magdeburgen ses centuriatores pro Canonibus Apostolorum, et Epistolis Decaestolibus Pontificum Apostolicorum. Livri. Quinque: Florentiae, ex Officina Bartholomei Sermortelli, Anno de 1572, este es un tomo de a folio forrado en Pergamino mui mal Tratado, digo que casi es de a folio, [un peso ${ }^{50 .}$

${ }_{48}$ Anotación manuscrita en la portada del libro de MANRiQue Luján, F.: Relacion de las fiestas de la ciudad de Salamanca, en la beatificacion de la sancta madre Teresa de Jesus, fundadora de la reformacion de los descalços, y descalças de nuestra señora del Carmen, por D. Fernando Manrique de Luxan. En Salamanca por Diego Cussio, 1615, Ejemplar BEFK 21566.

49 "Real Cedula, comprehensiva de la Instrucción de lo que se deberá observar, para inventariar Los Libros y Papeles exîstentes en las Casas que han sido de los Regulares de la Compañía, en todos los dominios de S.M., que contiene la "Instrucción de lo que se deberá observar, para inventariar los Libros, y Papeles existentes en las Casas, que han sido de los Regulares de la Compañía, en todos los dominios de S.M.”, en Colección General de las providencias hasta aqui tomadas por el Gobierno Sobre el estrañamiento y ocupación de las temporalidades de los Regulares de la Compañia que existian en los Dominios de S.M. de España, Indias, e Islas Filipinas à consequencia del Real Decreto de 27 de Febrero y Pragmática-Sanción de 2. de Abril de este año. De orden del Consejo, en el Extraordinario. En Madrid, en la Imprenta de la Gazeta, Año de 1767. Y por su original en México, en la Imprenta de los Herederos de Doña María de Ribera, 1768, pp. XVII, 65-73. Ejemplar de la Biblioteca Nacional de México (BNMx) RSM 1768 M4 ESP.

50 Índice de la biblioteca del colegio jesuita de San Luis Potosí, Archivo Histórico Nacional de España (AHN), Clero, Jesuitas, Legajo 91, núm. 67-77. Reproducción del negativo 2874, fol. 53v. 
También encontramos información sobre estas bibliotecas en las "Comisiones de expurgo". Documentos que mencionan tanto a las bibliotecas comunes y particulares de las fundaciones religiosas. Estas comisiones, que recientemente han sido identificadas ${ }^{51}$, confirman que efectivamente se realizó el procedimiento inquisitorial denominado visita de las bibliotecas. Sin embargo, dicha confirmación sólo aplica para las bibliotecas religiosas y no para las privadas del siglo, esas que también existieron en la sociedad novohispana. De estas, no hemos encontrado noticia alguna sobre una visita inquisitorial. Desde luego para la Inquisición implicaría una problemática adicional que no podría justificarse fácilmente. Hasta dónde sabemos esa inspección en el entorno privado, sólo se hizo cuando había razones fundadas y denuncias concretas.

Finalmente podemos mencionar otro documento interesante que los lectores, religiosos o civiles, presentaban ante la Inquisición cuando esta entidad así lo solicitaba. Regularmente tal petición se hacía al tiempo de publicación de un edicto o índice de libros prohibidos. En ese momento un lector debía informar sobre los libros que tenía en su poder. De ahí que aparezca escrito esa condición: "libros en uso" "de mi uso" o "en mi poder". Esta forma se relaciona también con las anotaciones de propiedad de muchos lectores novohispanos que encontramos en los libros y que los catalogadores denominan "ex libris manuscritos". Se trata de documentos que remiten siempre a la conformación de una biblioteca, pues el destino de dicha colección, dependerá directamente de la fortuna o infortunio de un lector. Así en noviembre de 1612, el agustino Juan de Galarza informó que tenía los libros siguientes:

Concordancias de Jansenio de Leon de francia por Pedro Landrino año de[1]586 Jansenio sobre los pecados dela dicha enprenta el dicho año

Maldonado sobre los Evangelios, en leon de francia por horaçio cordon año de[1]602

Molina De Justitia et Jure en Cuenca por Xpiano barnaba año de[1]592

Pineda in Job tomus 1 En Sevilla en El colegio dela Compañia año de[1]598

Pineda in Job tomus 2 de Sevilla en el dicho colegio ano De[1]602

Suarez in 3tiam Divi Thomae tomus 2 Enmadrid por Pedro madrigal año de [1]598

Suarez in 3tiam tomus 3 De salamanca por Joan y Andres Renaut año de [1]598

Monarchia de Çamora 2 partes en Caragoça por Alonso rodriguez año de [1]605

Vega sobre los pecados tomus 1 de Alcala por Juan miguez año de[1]599

El dicho tomus 2 De madrid por Serrano De Vargas año de[1]602

El dicho tomus 3 De madrid por el mismo impresor año de[1]603

Tabla del suso dicho ni tiene Impresor ni Año

quaresma De Santiago De Valladolid Por Luis sanches año de [1]606

Las concordançias de la biblia de Leon por Pedro Landrino año de[1]603

Historia de nuestra del padre Castro en Alcala por Joan Graçiano año de[1]605

Constituçiones Del orden de sant Augustin en salamanca por Guillermo foquel año de[1]595

Marques sobre los pecados En Medina del campo por pedro y Thomas Lasso año de[1]603

Justina lapicara En medina del campo por Xp[o]bal Casobaca año de[1]605

Summa De Toledo Deleon de françia por Horaçio cordon an[o] de [1]609

51 Inquisición de México. Año de 1716. 
Nombres de xpo de fray Luis de leon En salamanca por Thomas de Alba año de [1]603

Silbalo corum defray Luis de Granada En Leon por Simphoriano beraut año [1]586 Don quixote De la mancha En lisboa por Pedro crasnaeck año de[1]605

Refranes del comendador Griego En Valladolid por Luis sanchez año de[1]602

Compendio De Navarro en Leon por Horaçio Cordon An[o] de [1]603

Diogenes Laerçio de vita philosophorum en Leon por sebastian Grypho año de[1]551

opusculos De Xuarez en Leonpor Horaçio Cordon An[o] 1600

Joan Equio omellia En Paris por Andoenio parbo An[o] [1]549

Guia de pecadores fray Luis de Granada En Salamanca por Domingo partenario An[o] [1]569

Conçilio Tridentinus En salamanca por Juan baptista An[o] [1]571

Biblia Sacra en Antuerpia por Plantino Ano De [1]583

frases Italianas y Latinas que no tiene principcio ${ }^{52}$

Algunos de estos documentos, como el anteriormente transcrito, sorprenden por el detalle que proporcionan sobre las ediciones. En especial porque generalmente se piensa que en estos testimonios hay información muy básica que no permite identificar las obras del pasado. Por ejemplo, Queniart pensaba que en el registro de numerosas bibliotecas a finales del siglo XVII, las colecciones fueron totalmente o parcialmente estimadas en bloque, que la mención de las obras es frecuentemente alusiva, pues los títulos son truncos, los autores raramente precisados y los lugares y datos de impresión no son nunca indicados ${ }^{53}$. Ciertamente no todos los testimonios son iguales. Unos permitirán una identificación precisa de una edición conservada en un repositorio moderno y otros no. Lo cierto es que la disponibilidad de catálogos electrónicos de ediciones antiguas, permite identificar con mayor facilidad ediciones que estaban en ese momento histórico disponibles para la lectura. De esta manera, podemos dar un paso más que solamente mencionar de manera genérica los autores y las obras.

Las bibliotecas de las órdenes religiosas existieron "porque los libros son tan necessarios, que sin ellos no se puede administrar los oficios de más importancia de la Orden, y como son lo de los lectores, Predicadores y Confesores" ${ }^{54}$. Hay que considerar que se ha dado por válido el cálculo aproximado de 15,587 misioneros europeos que pasaron a las Indias entre 1493 y 1822, individuos que pertenecían primordialmente a las órdenes de San Francisco, la Merced, Santo Domingo, San Agustín, la Compañía de Jesús ${ }^{55}$. Esta suma no contempla a todos los religiosos americanos que se integraron al trabajo de todas las órdenes religiosas que tuvieron actividad en la Nueva España. Individuos que necesitaban libros, ya sea por los

52 Memoria de los libros que tiene fray Joan de Galarza, de la orden de San Agustín (1612), AGN, Indiferente virreinal, caja 4217, exp. 52, fols. 46r-46v. Expediente digitalizado.

53 Queniart, J.: "L'utilisation des inventaires en histoire socio-culturelle", en Vogler, B.: (ed.): Les actes notariés. Sources de l'Histoire sociale XVIe-XIXe Siècles: Actes du Colloque de Strasbourg (mars 1978), Strasbourg, Librarie Istra, 1979, p. 248.

54 SAn Joseph, M. (O.F.M.): Breue exposicion de los preceptos que en la Regla de los Frayles Menores obligan a pecado mortal segun la mente de los Sumos Pontifices y de S. Buenaventura. En Zaragoza, en el Hospital Real y General de Nuestra Señora de Gracia, 1638, p. 480. Ejemplar BNMx RFO 255.300906 MAR.b. 1638.

55 Datos calculados a partir de la información elaborada por Borges Morán, P.: El envío de misioneros a América durante la época española, Salamanca, Universidad Pontificia de Salamanca, 1977. 
requerimientos institucionales o incluso porque padecían de un mal mayor: el de la lectura. Esos libros fueron numerosos y muchos de estos tesoros de sabiduría, llegaron directamente en barco para satisfacción de sus lectores y probablemente para el disgusto de algunos santurrones.

\section{Las adquisiciones librescas de los religiosos}

Como habíamos precisado líneas atrás, Rueda mostró cómo participaban los religiosos en la Carrera de Indias para abastecer ciertas necesidades librescas. Algunos de esos testimonios, están relacionados directamente con sus tareas misionales y de evangelización como cartillas o breviarios. Hasta hace poco tiempo, no teníamos muchas noticias sobre las adquisiciones de libros en estas comunidades. Suponemos que como cualquier lector, los religiosos también acudirían a las librerías de su época e incluso acudirían a las almonedas de difuntos.

Sin embargo, dos evidencias históricas atestiguan una forma particular para hacerse de libros en la Nueva España. Un medio que compartían otros religiosos en todos los territorios de la América española. Nos referimos a los trabajos dedicados al Convento de San Juan Bautista en Coyoacán ${ }^{56}$ y al de San Agustín de la Puebla ${ }^{57}$. Dichos trabajos mostraron que estos religiosos pidieron libros directamente en Europa. Los dominicos a Diego de la Torre y, los agustinos, a los mercaderes Cristóbal Gutiérrez Rojo y Antonio de Toro.

Dicha evidencia permitía suponer que en la parte americana de los trámites, también debió quedar algo anotado sobre esas adquisiciones. El resultado de esta suposición no ha sido tan afortunado, pero sí ha dado uno que otro fruto más que interesante. Como este encargo comercial que los oratorianos hicieron al mercader Manuel Antonio Pérez:

[ ] por encargo del Padre Dimas de Lara del oratorio de San Philipe Neri en Queretaro, compre aqui quatro Breviarios que devian tener los santos de la orden de San Francisco y reconocidos alla, los devuelve porque dice que no los tienen, esta detenidos en esta Real Aduana, y para que los entreguen, se necesita pase de Vuestra Señoria Ylustrissima en esta atencion ${ }^{58}$.

No obstante, también encontramos otros documentos vinculados a las redes comerciales entre Europa y América. Estos han mostrado que las comunidades religiosas debieron hacer los mismos procedimientos aduanales e inquisitoriales, que libreros y mercaderes de libros. Cualquier desplazamiento de carácter personal se hizo cuando una persona viajaba para reunirse con algún familiar, cuando se había obtenido un empleo como funcionario en Indias, o cuando un religioso se integraba a una comunidad o a una misión. Cualquiera de estos traslados que se hiciera con libros debía ser notificado a los inquisidores prácticamente de la misma forma que

56 Wagner, K.: "Libros para el convento de Santo Domingo de Coyoacán”, Historiografia y bibliografía americanistas, 23 (1979), pp. 117-119.

57 Rueda Ramírez, P.: "El abastecimiento de libros de la biblioteca conventual de San Agustín de Puebla de los Ángeles a través de la Carrera de Indias (1609-1613)", Estudios de Historia Novohispana 44 (2001), pp. 17-43.

58 Oficios donde se informa al virrey de la entrada de cajones de libros a través de la real aduana (1791), AGN, Indiferente virreinal, caja 0944, exp. 2, fol. 5r. Expediente digitalizado. 
se ha descrito. Lo que significa que dicho control dejaría bastantes evidencias documentales que, al parecer, un grupo importante de estas se ha perdido.

Como sabemos, este transporte requería la presentación de una memoria de libros antes de embarcar sus productos, que consecuentemente se revisaba junto con los cajones de libros en el puerto de llegada antes de liberar la mercancía. Fue un procedimiento largo y engorroso, cuyos resultados también podían ser la pérdida irremediable de los libros adquiridos, lo que generaba quejas de los religiosos. Por esa razón, algunos de los provinciales argumentaron, basados en sus privilegios eclesiásticos, la posibilidad de acelerar o evadir los procedimientos que permitiera liberar los libros sin una nueva revisión. Esto implicaba que los cajones no se abrirían. Algunas de estas peticiones fueron aceptadas como la que aquí transcribimos:

Nos los del Consejo de su Majestad que entendemos en las cosas tocantes al ofizio de la Santa general Inquisizion etcetera $=$ A vos los Comisarios del Santo Ofizio de la Inquisizion que ay en los puertos de mar y secos de estos reinos, y a todos y a qualquier personas a cuio cargo esta la guarda de los puertos y pasos vedados que ay desde esta Corte hasta la Ciudad y puerto de la Veracruz en los Reinos de las Yndias, y a cada uno y qualquiera de vos que con esta nuestra Provision fueredes requerido o requeridos, sabed que el Padre Agustin Soler de la Compañia de Jesus y Procurador General de Philipinas, nos presento llevava a la Ciudad y Puerto de la Veracruz, dos caxones de libros de que presento memoria; y para que no se le pusiese ympedimento donde transitasen, nos suplico mandaremos dar el despacho nezesario; y por nos visto presente el Ilustrissimo Señor Obispo de Pamplona Ynquisidor General, fue acordado por decreto de oy dia de la fecha dar esta nuestra carta para vos y para uno de vos en la dicha razon = Por la qual os mandamos que luego que con ella fueredes requerido o requeridos por parte del dicho Padre Agustin Soler, dejeis pasar conduzir libremente los referido dos caxones de libros, hasta la expresada Ciudad y Puerto de la Veracruz, zerrados y sellados con el sello del santo oficio sin abrirlos [ni] ponerle ympedimento, pedir ni llevar derechos algunos; atento a que dichos libros son corrientes y no prohividos ni mandados recoger por el santo ofizio; lo qual así azed y cumplir pena de veinte mill maravedies para gastos del santo ofizio so lo qual dicha pena mandamos a qualquier escribano o notario que con ella fuere requerido os la notifique y de ello de testimonio. Dada en Madrid a veinte días del mes de Abril de mill setezientos y veinte y dos años. Licenciado Gaspar de, Licenciado Andres de la Cantolla Mier, Escribano de Reino y del Consejo ${ }^{59}$.

Afortunadamente no todos los religiosos obtuvieron esta merced. Por eso conservamos algunos documentos que sólo nos informan el número de cajones que se transportaron desde Europa a este territorio, otros que notifican lo contenido en esos cajones, y unos más con noticias curiosas. Entre estas aquellas que nos permiten saber que los mendicantes también participaron en la venta y distribución de libros, tanto de aquellos producidos bajo su patronazgo como de libros duplicados en sus bibliotecas. En este tenor, el jesuita Alponte informa con tal detalle al procurador Cristóbal de Lariz que: 
Con Idefias vecino de la Puebla, y dueño de recua escribi a Vuestra Reverendissima, remitiendole los quatro cajones de libros del Padre Alemán, deciale a Vuestra Reverendissima que avia vendido ocho tomos del Señor San Josef a seis pesos cada uno, que importaban 48 pesos, gaste 12 pesos que di al harriero, ytem ocho pesos de los quatro cajones, lias y petates 1 peso 4 reales, que todos son 21 pesos 4 reales: resto 26 pesos 4 reales. Del flete de España acá piden 45 pesos 3 reales. Yo me quede; o mejor decir, di un breviario de dos cuerpos al Vicario Castillo, y un juego de Filosofia a Don Diego Valverde a quien no pude negarme: estimare a Vuestra Reverendissima, que me avise de su valor para cobrar y pagar los 45 pesos 3 reales del flete; y si, como entiendo, Vuestra Reverendissima no corre con la venta de dichos libros sino el Hermano Ybarberola, estimare a Vuestra Reverendissima le lea este capitulo para que me avise Veracruz, Henero 27 de 1712. Muy siervo de Vuestra Reverendissima. Miguel de Aponte ${ }^{60}$.

Un comercio, español y americano, del que teníamos ciertas noticias por las portadas de los impresos. Aunque también lo habíamos visto en anotaciones que tienen los libros conservados:

Este Libro que era de la Libreria de San Pablo de México se vendió al Padre Predicador Fray Nicolás Ponze de León conforme la facultad que la Bula cita en dicha Libreria se confiere al Bibliotecario de ella, para poder vender con consentimiento del Prelado, los duplicados, y porque conste lo firme a 12 de Marzo de 1758. Fray Nicolas de Cardenas Bibliotecario ${ }^{61 .}$

Por otro lado, también tenemos evidencia sobre el envío de impresos cruciales para el funcionamiento interno de las órdenes religiosas como reglas, o en este caso un Bulario:

\section{Ylustrissimo Señor}

Suplico a vuestra Señoría Ylustrissima se sirva mandar dar el Passe de esse Santo Tribunal, à un cajón que con quarenta y cinco exemplares, ò libros que contienen el Bulario de mi sagrada Religion que esta detenido en la Aduana. Convento Bethlemitico de Mexico 9 de enero de 1777.

Fray Juan Agustin de San Ignacio ${ }^{62 .}$

Aquí queremos mostrar una parte de unos testimonios que informan sobre adquisiciones de libros, que alimentaron las diferentes bibliotecas de las órdenes religiosas para que se aprecie el tipo de información que contienen y pueda ser útil a otros estudios. Debemos aclarar que las noticias identificadas a la fecha del siglo XVII son sólo dos. Una, la del jesuita Francisco de Florencia quien en 1678 al terminar

\footnotetext{
60 "El Procurador General Christoval de Laris. Míguel de Asponte remite 4 cajones de libros del padre Hernán, al perecer se habían vendido ocho tomos a seis pesos cada uno. En lo que se refiere las cuentas, Se entregarán, se anexan las cuentas", AGN, Indiferente virreinal, caja 4036, exp. 13, fol. 2r. Expediente digitalizado.

${ }_{61}$ Anotación manuscrita en h.1v. del libro de AguILAR Y ZúÑIGA, E.: Corona de predicadores o predicacion de San Estevan dividida en tres partes... Con Privilegio en Madrid: María de, 1636. BNMx RFO 270.08 AGU.c.1636.

62 Petición de fray Juan Agustín de San Ignacio para envió de un cajón con libros detenido en la aduana para el Convento de Bethlemitico de México. Petición para el Santo Tribunal (1777), AGN, Indiferente virreinal, caja 2562, exp. 20, fol. 1r. Documento digitalizado.
} 
su cargo como procurador de las Provincias Jesuitas de América ${ }^{63}$, volvió con una importante lista de libros que suponemos era para comunidades jesuitas ${ }^{64}$. Otra, es la que notifica los cajones para el Convento de San Francisco de México de 1698, relacionados además con la beatificación de Sebastián de Aparicio ${ }^{65}$.

Tal escasez documental resulta comprensible por los diferentes eventos que afectarían la permanencia de la documentación virreinal. Podemos citar los motines sociales de 1624 y 1692, la gran inundación de la capital entre 1629 y 1634, así como el robo de la documentación para fines tan profanos como hacer cohetes en 1702, o para ser usados en la venta de bizcochos y pasteles en 1800. Lo cierto es que estos testimonios pueden documentar que los libros no sólo llegaron al territorio novohispano, sino que desde allí esos mismos libros se movieron a tierras más lejanas. En 18 de enero de 1716, un conjunto de libros emprendían de nuevo el viaje con destino a las Filipinas:

Fray Joseph de Pedro Bernardo Procurador de la Misión de Religiosos Franciscanos Descalzos que existen en el Hospital de San Agustín de las Cuevas, proximo a embarcarse para la Provincia de San Gregorio en las Yslas Philipinas se halla con los libros que expresa la lista firmada de su Comisario el Reverendo Padre Fray Pedro Lifante de la Concepción que en toda forma acompaña. Y deseando transportarlos para dicha Provincia se ha de dignar la Benignidad de Vuestra Señoria Ylustrissima conceder su licencia para el efecto. Por tanto, Vuestra Señoria Ylustrissima suplico se digne providenciar como lo pido ${ }^{66 .}$

Es muy probable que las autoridades religiosas, al realizar las compras en Europa, también debían hacerse cargo del envío o traslado de las adquisiciones bibliográficas hasta su destino. Los documentos coinciden en esta responsabilidad. Sin embargo, los testimonios conservados también narran las pérdidas de información. En 1695 se apuntó, al margen izquierdo, que el fraile presentó la memoria de los libros correspondiente, la cual contenía "el nombre de los autores y de los tratados":

Fray Manuel Sanchez de el orden de Nuestro padre San Francisco Predicador Jubilado, y Padre de la santa Provincia de Sacatecas ante vuestra Señoria parezco y digo = que haviendo trahido de los Reynos de Castilla un cajon grande de libros predicables, espossitivos, Morales y algunas Vidas de santos y juntamente dos petacas con otros que estan detenidos en la Aduana, que todos juntos haran ciento y veinte tomos pocos mas o menos de a folio y de a quartilla, y haviéndose registrado los dichos libros por le Señor Comissario de la Ciudad de Cadix del mandato del Santo Tribunal de la ciudad de Sebilla me concedio licencia para embarcarlos, y en el Puerto de la Veracruz le manifeste al Comissario de la Ciudad de la Veracruz,

63 Rubial García, A.: "Religiosos viajeros en el mundo hispánico en la época de los Austrias (El caso de Nueva España)", Historia Mexicana, 61-3 (2012), p. 824, https://unam.academia.edu/AntonioRubial (Consulta: 12 de Septiembre de 2016).

64 Memoria de los libros que ha comprado el Padre Procurador Francisco de Florencia para la provincia de Nueva España, y el costo de ellos (1678), AGN, Indiferente virreinal, caja 5707, exp. 5, 6 folios.

65 Diligencias que se hicieron por unos cajones de libros prohibidos que se detuvieron en la aduana de México y que estaban destinados al Convento de San Francisco de México. Se cita la causa del Beato Sebastián de Aparicio (1698). AGN, Inquisición 76, exp. 6, fol. 178r.-202r.

${ }_{66}$ Fray Joseph de Pedro Bernardo, Procurador de la Misión de Religiosos Franciscanos Descalzos del Hospital de San Agustín de las Cuevas, para llevar libros a Filipinas (1716), AGN, Indiferente virreinal, caja 3752, exp. 15, fol. 1r. Documento digitalizado. 
con cuyas licencias que presento los he trahido. A vuestra Señoria pido y suplico se sirva de mandar se me entreguen dichos libros, cajon y petacas que en ello requiere merced de la bondad de Vuestra Señoria Ilustrissima. Fray Manuel Sanchez ${ }^{67 .}$

La memoria citada no se ha encontrado todavía, desde luego no se conserva con el expediente. Aquí es importante apuntar que esas relaciones de libros, tienen una denominación diferente en la documentación histórica según sea el procedimiento para el que se elaboró. De esta manera podemos encontrar registro, inventario, lista, factura y memoria. Lo interesante de estos testimonios es que aquellos que se entregaban para trámites inquisitoriales siempre son más detallados que otros. Cuando se conserva la memoria, aun cuando esta no tenga los datos ideales, nos aporta información muy valiosa sobre los intereses librescos de los religiosos novohispanos. El agustino Fray Antonio, informó de los libros que adquirió:

San Laurentii Justin. Opera folio 1 tomo

San Gregorii Nisen Opera folio 3 tomos

San Ephren Opera Fixi folio 1 tomo

Revelationes San Birgitta folio 2 tomos

Petri Bercon Opera folio 5 tomos

Eusebij Pamphili Opera folio 3 tomos

Theophilaethi Opera folio 2 tomos

Philonij Heorji Opera folio 1 tomo

Theodorti Opera folio 1 tomo

Cocumenij Opera folio 2 tomos

Ruperti Abatis Opera folio 2 tomos

Procapij historia arcana folio 1 tomo

Ricadi de San Victore Opera folio 1 tomo

a Jesus Maria de Passione Nuestra folio 2 tomos

5 tomus Bullari Rom folio 1 tomo

San Thomas de Villanova Conciones quarto 3 tomos

San Vicente Ferrer Conciones octavo 3 tomos $^{68}$

Los libros se compran incluso para aquellas instituciones que son la continuidad de otras con un brillante pasado. Así fueron los libros que se adquirieron para el Colegio de San Buenaventura en $1777^{69}$, fundado en 1667, en el mismo edificio que estuvo el Colegio de Santa Cruz de Tlatelolco. Este último fue una de las instituciones franciscanas más antiguas y de mayor estimación en la historia novohispana, fundado en 1535 para la formación de los hijos de la nobleza indígena en donde aprendían el trivium y el quadrivium. Es decir, "gramática, retórica y lógica, por una parte y aritmética, geometría, astronomía y música, por la otra, medicina tradicional y, por supuesto, doctrina cristiana y conceptos básicos de teología"70.

67 Solicitudes de licencias al Santo Oficio (1665-1699), AGN, Indiferente virreinal, Caja 0791, exp. 13, fol. 10r.

68 Memoria de los libros [...] para el Reverendo Padre Maestro Fray [Antonio... ] orden de San Agustin (s.f.), AGN, Indiferente Virreinal, Caja 2118, exp. 2, 1 folio. Expediente digitalizado.

${ }_{69}$ Fr. Francisco Sánchez Valverde, de la regular observancia de Nuestro Santo padre San Francisco, morador en el Colegio de San Buenaventura, solicita el pase correspondiente para recoger 4 cajones de libros que le remiten de Jalapa (1777), AGN, Inquisición 1100, exp. 6, fol. 237r.

70 Máynez, P.: "El Colegio de Santa Cruz de Tlatelolco, recinto de saberes en el México novohispano", WaLdE, L. y Reynoso Inglis, M.: (ed.), Virreinatos II,. México, Destiempos, 2013, p. 71. 
Este colegio de Santa Cruz también fue un centro de formación que intentó formar un clero de indios ${ }^{71}$, hasta su prohibición por el Concilio Mexicano de 1555. Por su parte el Convento de Tlatelolco, fundado en 1536, tenía su propia biblioteca de la cual se conservan tres inventarios del siglo XVII. Sin embargo, no tenemos certeza si la colección del Colegio de Santa Cruz se utilizó para iniciar la de San Buenaventura. Como mencionábamos, Francisco Sánchez Valverde, adquirió libros para este colegio 110 años después de su fundación ${ }^{72}$. Fueron cuatro cajones marcados con una "FMB". El documento no indica quién realizo las compras en Europa, pero debió ser el mismo responsable del trámite aduanal e inquisitorial y seguramente de elaborar esta relación:

2. juegos de Berti Theologia en 3 tomos de â folio cada uno

1. Juego de Frasen Disquisiciones Biblicas folio 2 tomos

1. De Graveson Historia Ecclesiastica en quarto 7 tomos

2. De Palavicino Historia Concilii 3 tomos en uno dorados

1. De Orsi Historia Ecclesiastica en quarto 23 tomos

2. De Habert Theologia en octavo 8 tomos

1. de Ferrari Bibliotheca en folio 4 tomos

1. De Houdri Opera Omnia en folio 8 tomos

1. De Tourneli en quarto 14 tomos

1. del Año Cristiano en quarto 18 tomos

2. De Theologia Moral de Natalen en folio 2 tomos

1. De Historia Ecclesiastica del mismo en folio 9 tomos

1. De la Madre Agreda del mismo en folio 3 tomos

1. De Potesta Examen Ecclesiastico en folio

1. De Labarri Sermones traducidos del frances en quarto 7 tomos

1. Del Teatro Critico en quarto 15 tomos

1. De Lohner Bibliotheca en folio 4 tomos

1. De Flores España Sagrada en quarto 32 tomos

1. Del Espectaculo de la Naturaleza en quarto 16 tomos

1. Del Catecismo de san Pio V en octavo

1. De Moheanos Historia Literaria en quarto 5 tomos

1. De Lajuan Sermones en quarto 4 tomos

1. De Bosuet Varios Tratados en quarto 22 tomos

1. Del mismo Parayso del Alma 16

1. De las obras de Amort en folio 6 tomos, 12 en quarto y 2 en octavo

1. De Antoino Theologia Moral 1 folio

1. De Duhamel Biblia en folio 2 tomos 3 tomos

1. Concordancias en folio

1. De Frasen Filosofia 2 tomos

1. De Aburta Filosofia en quarto 3 tomos

1. De Ferrari Filosofia en quarto 3 tomos

71 Morales, F.: "La alta educación de los franciscanos para los indígenas", Diario de Campo, 3 (2011), p. 84, www.revistas.inah.gob.mx/index.php/diariodecampo/article/download/3385/3268 [Consulta: 7 de Diciembre de 2016].

72 Fr. Francisco Sánchez Valverde, de la regular observancia de Nuestro Santo padre San Francisco, morador en el Colegio de San Buenaventura, solicita el pase correspondiente para recoger 4 cajones de libros que le remiten de Jalapa (1777), AGN, Inquisición 1100, exp. 6, fol. 237r. 
1. De Fray Arroros Sermones en quarto 6 tomos

1. De Fray Luis Retorica en quarto

1. De Señeri en quarto 15 tomos

1. De Bocanegra Sermones en octavo 2 tomos

1. De Breviarios en octavo 4 tomos con diurno y semanario

1. Del Compendio de la Religion en octavo 2 tomos

1. De Reinsestuel en quarto ${ }^{73}$.

Como se aprecia se trató de una selección de libros para la formación religiosa con varios autores emblemáticos, cuyo costo debió ser considerable porque suponemos que se trata de ediciones recientes. También encontramos unos cuantos libros ilustrados que hablan de la actualidad de la colección. Estos "quatro caxones de libros" se enviaron al fraile que, según la información, era morador del Colegio de San Buenaventura en 1774. Muchos religiosos también fueron responsables de que algunos "viajeros" bibliográficos que los acompañaban, cambiaran de aires y de lectores. La huella de esos derroteros también ha quedado patente en sus hojas, folios y encuadernaciones, aunque todavía no sepamos a cuál de todas las colecciones perteneció ese libro. Los testimonios localizados por ahora, sólo nos permiten acercarnos a la historia de tales eventos para contribuir al conocimiento de la cultura escrita en la América Española.

\section{Una reflexión final: los libros necesarios}

Aunque siempre se ha pensado que los controles sobre los libros de la Corona y la Inquisición, impactaron negativamente el desarrollo cultural o redujeron la llegada a América de los libros producidos en los grandes centros tipográficos de Europa, lo cierto es que quedan muchos testimonios que desmienten esas versiones. En estos territorios tan exentos, diversos y hasta exóticos, nunca faltaron libros ni evidencia documental de ello. Irving A. Leonard, Francisco del Castillo o Edmundo O'Gorman, son tan sólo algunos de los investigadores que mostraron las enormes vetas que se conservan en el Archivo General de la Nación desde la primera mitad del siglo XX. Pese a esa riqueza pareciera que la cultura del libro en la Nueva España no logra consolidarse como un tema de interés histórico, en estricta comparación a lo que esa temática ha avanzado y aportado en el mundo. Ya lo apuntaba Chevalier hace casi cuarenta años: "sería de desear que se emprendiera un estudio más detallado y completo de tan rica veta" 74 .

Afortunadamente algunos investigadores han compartido este deseo. Sin embargo, poco se ha hecho por documentar el movimiento de los libros, tanto como a mercaderes, libreros, y lectores. Tristemente son muy escasas las excepciones. Existe una realidad inexorable: de numerosas personas del pasado apenas si ha quedado huella en los repositorios. En ocasiones no podemos saber más que su nombre, sin familia, ni origen ni destino. Pero los libros representan un trazo inapelable de esas personas y de ese pasado que no debemos descartar. La historia de los libros, de

\footnotetext{
73 Factura de cuatro cajones de libros que con la marca y números del margen remitió al Reverendo Padre Francisco Sánchez Valverde, Religioso de Nuestro Santo Padre San Francisco en el Colegio de Santiago de México (s.f.), AGN, Indiferente virreinal, caja 5271, exp. 78, 1r-1v. Documento digitalizado.

74 Chevalier, M.: Lectura y lectores en la España del Siglo XVI y XVII, Madrid, Turner,1976, p. 49.
} 
las bibliotecas, del comercio libresco, de los lectores, de censores y calificadores e incluso de los autores y de la producción de los libros, es "en primera instancia, una historia de la cultura material de una sociedad"75.

Somos afortunados con el legado bibliográfico que hemos heredado, pues conservamos libros que nos dicen de quién fueron, dónde vivieron, cómo llegaron. Los libros anotados son otro universo que nos acercaría directamente al estudio de la lectura, aunque se dificulte mucho identificar a un lector. Los libros marcados cuentan sus traslados de un sitio a otro, y todas estas huellas se conjuntan en el espacio cotidiano de las órdenes religiosas y, especialmente en el que corresponde a las bibliotecas conventuales. Estas, aunque no son las únicas, resultan ideales para comprender el lugar y la función de los libros durante la vigencia del Virreinato de la Nueva España. En efecto, que existieran colecciones bibliográficas de naturaleza institucional y privada en las fundaciones religiosas, nos ayuda a comprender el número de ejemplares conservados. Las bibliotecas comunes se abastecían de diferentes ofertas, pero también recibieron los libros de los difuntos ${ }^{76}$. De ahí que no resulte extraño que con el tiempo existieron obras duplicadas, que se distribuyeron en casas menos afortunadas en sus recursos o más aisladas de los circuitos de distribución, también se vendieron a personas ajenas a esta vida religiosa.

Por otro lado, no debemos olvidar el comercio de segunda mano que permitía a ciertos lectores acceder a obras que pudieron estar agotadas, fuera de circulación o cuyo costo excedió las más nobles intenciones. Dicho comercio permite suponer que las adquisiciones de los religiosos novohispanos que se realizan por sus propias redes, buscan ediciones concretas y novedades que el mercado interior no puede satisfacer o que eleva el costo de su financiamiento. El mercado del libro en la Nueva España, no fue escaso y además fue constante a pesar de todas las dificultades. Las memorias de libreros y de lectores son prueba de ello. Para los mercaderes, los religiosos representarían una oportunidad ideal de negocio por lo que no parece que la hayan descuidado. Analizar todas estas aristas debe conducir a comprender mejor esas bibliotecas y el complejo comercio librario.

Por eso esta tarea no puede quedar en meramente localizar y transcribir las listas de libros, sino en intentar dar un paso más allá. Aquí sólo podemos mostrar la veta documental que representan, el significado de estos libros en el contexto cultural de su época requiera mayor detalle. Por ejemplo apreciar cómo el Padre Galarza junto a todos su libros de estudio, que aquí enumeramos, también poseía dos obras emblemáticas más cercanas al entretenimiento: la Picara Justina y el Quijote, ambas obras impresas en 1605, pero en ese momento no se trataba de la edición madrileña del compañero de Rocinante, sino la edición lisboeta.

75 Gonzalo SÁnchez-Molero, J. L.: "La situación actual y nuevas líneas de investigación sobre el libro y las bibliotecas en la Edad Moderna", en LABrador Arroyo, F. (ed.): II Encuentro de Jóvenes Investigadores en Historia Moderna. Líneas recientes de investigación en Historia Moderna, Madrid: Universidad Rey Juan Carlos, 2015, p. 92.

76 Estatutos, y ordenaciones de la Santa Provincia de San Gregorio de Religiosos Descalzos de la regular, y mas estrecha observancia de N.S.P.S. Francisco de Philipinas: dispuestas, y ordenadas por el compromisso de el Discretorio, y Diffinitorio en el Capitulo Provincial celebrado en nuestro convento de Nuestra Señora de los Angeles de la ciudad de Manila el dia 8 del mes de Iunio del año de 1726: Y mandadas dar à estampa por el Ministro Provincial, y Venerable Difinitorio el año de 1730. [Manila], Reimpresso en el Convento de Nuestra Señora de Loreto del pueblo de Sampaloc, 1753, p. 95 Ejemplar UCM BH FG 3050, disponible en Google Books. 
Por eso después de esto, debemos intentar encontrar con mayor precisión a aquellos supervivientes bibliográficos de un pasado tan rico como complejo. En esta aventura importa tanto la colección como la institución y sus personajes. La tarea no es fácil, pero muchas escuelas historiográficas ya han mostrado los numerosos caminos metodológicos que podemos abordar. Algunos de estos senderos se han hecho en absoluta soledad y otros, en el vórtice de los intereses compartidos. Es la experiencia que dejan los textos publicados en otras latitudes y en esta temática, que desbordan las aspiraciones de cualquier buena intención de lectura. Sin embargo, como hemos comprobado habrá que reconsiderar categorías, apreciaciones y valoraciones previas para comprender la documentación novohispana.

Todos los libros y documentos que testimonian las características de la cultura escrita en esta geografía virreinal, siguen siendo testigos históricos excepcionales. Es indudable que el rastro histórico de una edición antigua registrada con todos sus datos, permitiría identificar a las otras que fueron anotadas sólo con su autor, con su título, o la combinación de ambos. Los estudios que hemos hecho con bibliotecas privadas de la misma época, permiten suponer que no es una idea peregrina. Sin embargo, debemos entender a las fuentes históricas como lo que son, no como lo que queremos que nos digan. Ninguna de las evidencias aquí mencionadas fue elaborada para nuestro deleite o sufrimiento, sino para realizar un trámite específico.

De ahí que sea inevitable descifrar la naturaleza jurídica de los procesos, pero también las prácticas culturales que estos moldearon o impusieron. Más allá, los libros y las bibliotecas del pasado novohispano representan una heredad cultural que merece una valoración más acorde a su riqueza. Sin la investigación histórica, el problema patrimonial que representan seguirá obteniendo respuestas poco acertadas para asegurar su transmisión en el tiempo. Nos guste o no, siguen en riesgo, pero esa es otra historia para contar. 